\title{
RECICLAGEM QUÍMICA DE ZEÓLITAS COMERCIAIS DESATIVADAS
}

\author{
Júlio Carlos Afonso*, Alexandre Barboza Pontes, Emmanuel Soares Santos, Mayko de Sousa Menezes e Renata de \\ Melo Aguiar
}

Departamento de Química Analítica, Instituto de Química, Universidade Federal do Rio de Janeiro, CT, Bloco A, CP 68563, 21949-900 Rio de Janeiro - RJ

Recebido em 24/3/03; aceito em 21/7/03

\begin{abstract}
CHEMICAL RECYCLING OF SPENT COMMERCIAL ZEOLITES. Pyro and hydrometallurgical processes were applied to the treatment of spent commercial zeolites (a molecular sieve and a ZSM-5 sample). Both catalysts were employed in pilot plant units. They were kept in their original shape, they were not regenerated and were not subjected neither to mechanical stress nor to overheating zones during their time on-stream. Two recycling processes were tested: (i) direct solubilization of samples in mixtures of $\mathrm{HF}+\mathrm{H}_{2} \mathrm{O}_{2}\left(60^{\circ} \mathrm{C}, 1 \mathrm{~h}\right)$. Although silicon was solubilized, insoluble matter was found in both samples, particularly in the molecular sieve, due to its high amounts of alkaline and alkaline-earth metals; (ii) fusion with $\mathrm{KHSO}_{4}\left(5 \mathrm{~h}, 600{ }^{\circ} \mathrm{C}\right)$ with $\mathrm{KHSO}_{4}$ /zeolite mass ratio 6:1. After fusion the solid was solubilized in water $\left(100{ }^{\circ} \mathrm{C}\right)$, leaving silicon as $\mathrm{SiO}_{2}$ residue. In both processes, solubilized metals were isolated by conventional selective precipitation techniques. Analysis of final products by common analytical methods shows that metals present in the original catalysts were recovered with very high yields except when the molecular sieve was treated with $\mathrm{HF}+\mathrm{H}_{2} \mathrm{O}_{2}$. This reactant mixture proved to be suitable for processing zeolites with a low alkaline and alkaline-earth metal content whereas fusion with $\mathrm{KHSO}_{4}$ appeared to be adequate for all types of zeolites.
\end{abstract}

Keywords: spent catalyst; metal recovery; environment.

\section{INTRODUÇÃO}

Com a descoberta da stilbita, em 1756, as zeólitas (do grego zeo, ferver + lithos, pedra) foram reconhecidas pela primeira vez pelo mineralogista sueco Baron Axel Frederick Consted, o qual não conseguiu concluir que o mineral "fervia" sob aquecimento por causa da água armazenada em seus microporos. Em 1845, Way descobriu que determinados solos tinham a propriedade de reter sais de amônia, e Breck constatou que os silicatos hidratados de alumínio no solo eram os responsáveis pela troca iônica ${ }^{1,2}$.

Em 1925, Weigel e Steinholf foram os primeiros a constatar que a zeólita chabazita absorvia seletivamente moléculas orgânicas menores e rejeitava as maiores. Em 1932, McBain denominou esse fenômeno de peneiramento molecular ${ }^{1,3,4}$. Nas décadas de 40 e 50 , as pesquisas sobre as propriedades das zeólitas tomaram um grande impulso ${ }^{1-6}$.

Em 1962, a partir da aplicação pioneira em processos de craqueamento de petróleo, as zeólitas assumiram a posição de catalisadores de suma importância na indústria química ${ }^{7-10}$. O uso de zeólitas nesses processos continua a ser uma importante aplicação prática. Outros processos industriais catalisados por zeólitas são: a isomerização de xileno, a alquilação de benzeno, a produção de gasolina a partir de metanol e o hidrotratamento ${ }^{3,7-9}$. Outros usos comerciais são descritos na literatura ${ }^{2,5}$.

Quimicamente ${ }^{1,2,4}$, as zeólitas abrangem os aluminossilicatos cristalinos hidratados, de estrutura aberta, constituída por tetraedros $\mathrm{TO}_{4}$ ( $\mathrm{T}=\mathrm{Si}, \mathrm{Al}, \mathrm{B}, \mathrm{Ge}, \mathrm{Fe}, \mathrm{P}, \mathrm{Co} . .$.$) ligados entre si através de átomos de$ oxigênio. Nas zeólitas mais comuns, na fórmula $\mathrm{TO}_{4}, \mathrm{~T}$ representa o Si ou o Al. A fórmula química por célula unitária é:

$\mathrm{M}_{\mathrm{x} / \mathrm{n}}\left[\left(\mathrm{AlO}_{2}\right)_{\mathrm{x}}\left(\mathrm{SiO}_{2}\right)_{\mathrm{y}}\right] \cdot \mathrm{m} \mathrm{H}_{2} \mathrm{O}$

*e-mail: julio@iq.ufrj.br onde $\mathrm{M}$ é o cátion de valência $\mathrm{n}, \mathrm{m}$ é o número de moléculas de água e $(\mathrm{x}+\mathrm{y})$ é o número de tetraedros por célula unitária. Considerando a carga trivalente do alumínio em especial, os tetraedros $\mathrm{AlO}_{4}$ induzem cargas negativas na estrutura das zeólitas. Estas cargas são neutralizadas por cátions de compensação passíveis de troca. As zeólitas são catalisadores eficientes porque a aproximação forçada entre moléculas reagentes sob a influência dos fortes potenciais eletrostáticos existentes no interior dos canais e cavidades provoca o abaixamento da energia de ativação necessário ao fenômeno da catálise.

A produção mundial de zeólita sintética é estimada em 1,5 milhões t/ano, sendo que grande parte se destina à manufatura de detergentes, e cerca de 1/3 aos processos catalíticos ${ }^{2,7}$. A produção brasileira (Fábrica Carioca de Catalisadores), da ordem de 25 mil t/ano, é destinada ao craqueamento catalítico de petróleo.

O motivo pelo qual a utilização de zeólitas como catalisadores ácidos sólidos (catálise heterogênea) tornou-se uma tecnologia promissora foi, principalmente, por conta das vantagens que tais catalisadores mostram em relação aos tradicionais catalisadores ácidos homogêneos. A acidez da zeólita encontra-se no seu interior, portanto pode ser manuseada muito mais facilmente do que, por exemplo, o ácido sulfúrico, um líquido altamente corrosivo. Além disso, alguns tipos possuem acidez cerca de 10 milhões de vezes mais forte do que o ácido sulfúrico concentrado ${ }^{1,2,4}$.

Tendo em vista todos esses fatores, as zeólitas poderiam ser um grande bônus para o meio ambiente; por isso, foram inicialmente consideradas como resíduo não perigoso pela EPA (Agência NorteAmericana de Proteção ao Meio Ambiente). Entretanto, em 1996, a própria agência foi obrigada a reavaliar seus conceitos a respeito desses materiais catalíticos originariamente tão fabulosos ${ }^{7-9,11}$. O fato é que, após serem usados, nas unidades petroquímicas em especial, tais catalisadores tornam-se poluentes em potencial (de fato, um dos piores contaminantes oriundos de refinaria de petróleo) devido a três fatores básicos: o teor normalmente considerável de metais pesados; a presença de compostos altamente cancerígenos presentes nos ine- 
vitáveis depósitos carbonáceos (coque), que se alojam sobre sua superfície no decorrer de seu uso (a principal causa de desativação das zeólitas ${ }^{12}$ ); a elevada ácido-basicidade desses materiais, muito superior à dos solos. Em 1998, a EPA publicou uma listagem final de considerações sobre resíduos perigosos, em especial aqueles gerados nas refinarias de petróleo ${ }^{7-9}$, e revisada em $2002^{10,13}$. Nesta norma, a EPA caracterizou definitivamente os catalisadores usados das unidades de hidrotratamento, hidrorrefino, hidroprocessamento e hidrocraqueamento como resíduos perigosos, dentre os quais figuram as zeólitas. O tratamento prescrito antes do descarte é uma oxidação a alta temperatura, que visa eliminar o coque, insolubilizar os componentes inorgânicos (eliminando a acidez do sólido), mas é altamente consumidora de energia. Dada a produção mundial e a periculosidade intrínseca das zeólitas deativadas, o aproveitamento desse material usado, dentro de uma perspectiva de desenvolvimento de tecnologias limpas, torna-se vital. Dados de 1995 indicam um descarte, a nível mundial, de quase 500.000 toneladas de zeólitas de craqueamento de petróleo ${ }^{7-9}$.

Quando as causas de desativação são reversíveis, como no caso da deposição de coque sobre a superfície do catalisador zeolítico ${ }^{4,12}$, é possível recuperar a atividade catalítica original, através da remoção do coque presente (regeneração) ${ }^{12}$. Ainda assim, a queima controlada do coque não pode ser usada indefinidamente, uma vez que, afora a recuperação da atividade catalítica, o catalisador sofre, gradativamente, uma degradação estrutural, o que caracteriza um limite ("prazo de validade" conhecido como número de campanhas do catalisador) na reutilização dos catalisadores zeolíticos ${ }^{4}$.

As zeólitas desativadas não são muito mencionadas como matéria-prima em estudos de recuperação de elementos presentes ${ }^{2,7,10}$. A solução mais citada ${ }^{14-16}$ é a utilização das mesmas em cimenteiras, onde fazem parte do clínquer; nas altas temperaturas reinantes nos fornos, o coque é eliminado e a matéria inorgânica é convertida em formas insolúveis, após o emprego do cimento produzido. O emprego de zeólitas diretamente como matéria-prima é vantajoso, pois não há a preocupação de isolar os elementos que as compõem. Mas o uso desse material como ingrediente exige um criterioso controle de sua composição e do teor das impurezas metálicas presentes (níquel e vanádio, por exemplo), de forma a não alterar as propriedades do cimento (tornando-o fora de especificações) e dar a ele características tóxicas durante o manuseio ${ }^{10,13}$. Outro aspecto é o caso de zeólitas contendo metais nobres em sua formulação. Dado o elevado valor agregado desses metais e de seus compostos, há interesse econômico em recuperá-los o que, no entanto, exige o processamento integral da zeólita desativada, assunto pouco comentado na literatura. O gerenciamento dos resíduos de alumínio e de silício gerados nesses procedimentos passa a ser de vital importância para que os processos, como um todo, tenham compatibilidade ambiental; esses novos resíduos devem ter alguma utilidade em outros processos industriais.

Este trabalho teve por objetivo processar zeólitas usadas sob condições industriais, visando obter novos produtos de valor comercial, ou novas matérias-primas para a indústria química. Foram empregados métodos convencionais de tratamento por fusão. Em outra série de experimentos, tentou-se recuperar componentes dessas zeólitas empregando soluções contendo o íon fluoreto, aproveitando suas propriedades complexantes, o que permite utilizar condições experimentais brandas (tempo e temperatura) como aplicadas em nosso laboratório a outros tipos de catalisadores ${ }^{17}$.

\section{PARTE EXPERIMENTAL}

\section{Descrição das zeólitas}

Foram estudadas duas zeólitas - uma peneira molecular (zeólita
A, estrutura do tipo $\mathrm{LTA}^{1}$ ), contendo sódio e pequenos teores de cálcio e de ferro e uma amostra de ZSM-5 (estrutura MFI'1), componente de um catalisador comercial de craqueamento, contendo níquel, fósforo, vanádio, titânio, lantânio, cério, praseodímio, neodímio e vanádio. A peneira molecular foi empregada na etapa de secagem de cargas brutas de hidrocarbonetos $\left(60^{\circ} \mathrm{C}, 1,5 \mathrm{~atm}\right)$, enquanto que a outra amostra foi usada em processo de craqueamento em unidade piloto industrial de FCC. Suas formas originais eram pó fino (ZSM5) e extrudados cilíndricos (peneira molecular). Não foram regenerados, não sofreram desgastes mecânicos, nem picos de temperatura ("overheating zones") no leito catalítico durante suas vidas úteis. Suas composições são apresentadas na Tabela 1 .

Tabela 1. Composição química das zeólitas estudadas

\begin{tabular}{ccc}
\hline Elemento (como óxido) & Peneira Molecular & ZSM-5 \\
\hline $\mathrm{SiO}_{2}$ & $46,80 \pm 0,24$ & $59,20 \pm 0,34$ \\
$\mathrm{Al}_{2} \mathrm{O}_{3}$ & $23,20 \pm 0,20$ & $36,50+0,21$ \\
$\mathrm{Na}_{2} \mathrm{O}$ & $28,50 \pm 0,25$ & - \\
$\mathrm{CaO}$ & $1,07 \pm 0,01$ & - \\
$\mathrm{NiO}$ & - & $0,11 \pm 0,02$ \\
$\mathrm{~V}_{2} \mathrm{O}_{5}$ & - & $0,09 \pm 0,01$ \\
$\mathrm{TiO}_{2}$ & - & $0,36 \pm 0,02$ \\
$\mathrm{P}_{2} \mathrm{O}_{5}$ & - & $0,58 \pm 0,01$ \\
$\mathrm{Fe}_{2} \mathrm{O}_{3}$ & $0,42 \pm 0,03$ & $0,49 \pm 0,03$ \\
$\mathrm{C}$ & - & $2,62 \pm 0,06$ \\
$\mathrm{Ln}_{2} \mathrm{O}_{3}(\mathrm{Ln}=\mathrm{La}, \mathrm{Ce}, \mathrm{Pr}, \mathrm{Nd}$ e Sm) & - & $0,03 \pm 0,01$ \\
\hline
\end{tabular}

* obtidos por absorção atômica, exceto o carbono (combustor Leco); valores expressos em \% (p/p) com intervalo de confiança a $95 \%$

\section{Seqüiência de experimentos - fusão com $\mathrm{KHSO}_{4}{ }^{6,18}$}

Ambos os materiais foram postos à fusão, utilizando para isso o fundente bissulfato de potássio, $\mathrm{KHSO}_{4}$, (fusão ácida não oxidante), em mufla a $600{ }^{\circ} \mathrm{C}$ por $5 \mathrm{~h}$. Com base nos dados de composição dos catalisadores, estabeleceu-se uma razão fundente/catalisador em 6:1 (p/p). O catalisador foi previamente pulverizado em gral de vidro e intimamente misturado com o fundente. A mistura foi efetuada no próprio cadinho da fusão, com o auxílio de um bastão de vidro de ponta arredondada. Findo o processo de fusão, o cadinho foi resfriado em dessecador e, em seguida, o conteúdo foi desagregado com água a $90-100{ }^{\circ} \mathrm{C}$, com agitação manual ocasional, por $30 \mathrm{~min}$.

\section{Seqüência de experimentos - tratamento com $\mathrm{HF}+\mathrm{H}_{2} \mathrm{O}_{2}{ }^{17}$}

As amostras foram previamente tratadas por oxidação em mufla a $1000{ }^{\circ} \mathrm{C}$ por $5 \mathrm{~h}$ (1 atm) a fim de eliminar o coque, permitindo maior difusão dos reagentes através da superfície. Em seguida, o material foi tratado com misturas $\mathrm{HF}(40 \% \mathrm{p} / \mathrm{p})+\mathrm{H}_{2} \mathrm{O}_{2} 36 \% \mathrm{p} / \mathrm{p}$ $(1: 1 \mathrm{v} / \mathrm{v})$ sob temperatura e agitação variáveis. As massas da zeólita e de $\mathrm{HF}$ foram calculadas de modo que o íon $\mathrm{F}^{-}$complexasse todos os metais com excesso de $10 \%$ p/p em relação ao teórico, ou então em relação à precipitação de fluoretos insolúveis.

\section{Métodos analíticos}

Os metais (em solução) foram analisados por absorção atômica (Perkin Elmer AAS 3300), cujos limites de detecção, determinados experimentalmente, são Al: $0,5 \mathrm{mg} \mathrm{L}^{-1}$; Fe e Ti: $0,05 \mathrm{mg} \mathrm{L}^{-1}$; Ni, La e Ce: $0,1 \mathrm{mg} \mathrm{L}^{-1}$; Si e V: $1 \mathrm{mg} \mathrm{L}^{-1}$. O teor de carbono foi determinado via análise elementar (Combustor LECO). Lançou-se mão, também, 
da gravimetria (pesagem dos resíduos insolúveis das aberturas). Os íons $\mathrm{Na}^{+}, \mathrm{Ca}^{2+} \mathrm{e} \mathrm{F}^{-}$foram dosados através da cromatografia de íons (Dionex DX 100, limite de detecção $0,01 \mathrm{mg} \mathrm{L}^{-1}$ ). A difração de raios-X foi usada para análise de diversos sólidos obtidos na etapa de isolamento dos elementos após a dissolução dos catalisadores (difratômetro PHILIPS PW 1820; fonte de radiação $\mathrm{Cu}-\mathrm{K} \alpha$, varredura angular (2 teta) $12-70^{\circ}$, com passo de $0,020^{\circ}$ e tempo de $1 \mathrm{~s}$ por passo; as amostras apresentavam granulometria menor que $0,0044 \mathrm{~nm}$ ). As dosagens quantitativas foram complementadas por análises qualitativas ${ }^{19-20}$ para as soluções e os sólidos.

\section{RESULTADOS E DISCUSSÃO}

\section{Fusão com $\mathrm{KHSO}_{4}$}

Após a fusão e tratamento com água da massa fundida, observou-se em ambos os casos a deposição de um sólido branco, brilhante e muito fino, que foi isolado do meio por centrifugação. Após lavagem com água e secagem em estufa a $150{ }^{\circ} \mathrm{C}$ por $1 \mathrm{~h}$, verificouse que este sólido correspondia ao dióxido de silício, cuja massa obtida concordava exatamente com a composição descrita na Tabela 1 para os catalisadores em estudo. A difração de raios-X confirmou que o material tinha um espectro idêntico ao da sílica. Para os demais componentes das zeólitas propõem-se as seguintes reações:

$$
\begin{aligned}
& \mathrm{XO}+2 \mathrm{KHSO}_{4} \rightarrow \mathrm{XSO}_{4}+\mathrm{K}_{2} \mathrm{SO}_{4}+\mathrm{H}_{2} \mathrm{O} \quad \mathrm{X}=\mathrm{Ca}, \mathrm{Ni} \\
& \mathrm{Y}_{2} \mathrm{O}_{3}+6 \mathrm{KHSO}_{4} \rightarrow \underset{\mathrm{Y}_{2}\left(\mathrm{SO}_{4}\right)_{3}+3 \mathrm{~K}_{2} \mathrm{SO}_{4}+3 \mathrm{H}_{2} \mathrm{O}}{\mathrm{Y}=\mathrm{Al}, \mathrm{Fe}, \mathrm{La}, \mathrm{Ce}, \mathrm{Pr}, \mathrm{Nd}, \mathrm{Sm}} \\
& \mathrm{TiO}_{2}+2 \mathrm{KHSO}_{4} \rightarrow \\
& \mathrm{NiO}_{2} \mathrm{O}\left(\mathrm{SO}_{4}\right)+\mathrm{K}_{2} \mathrm{SO}_{4}+\mathrm{H}_{2} \mathrm{O} \\
& \mathrm{NHSO}_{4} \rightarrow \mathrm{Na}_{2} \mathrm{SO}_{4}+\mathrm{K}_{2} \mathrm{SO}_{4}+\mathrm{H}_{2} \mathrm{O}
\end{aligned}
$$

$\mathrm{O}$ pH da solução após a dissolução da massa fundida situou-se na faixa 2-3, ácida o suficiente para impedir a precipitação do $\mathrm{V}$ e do $\mathrm{P}$ presentes na zeólita ZSM-5.

De acordo com a zeólita utilizada, em função dos elementos presentes, foram elaboradas duas seqüências de fracionamento, a partir da solução após a remoção do silício:

a) fracionamento da solução - Peneira molecular (Figura 1): a primeira etapa é a primordial para o sucesso do processo de separação: gotejou-se, à temperatura ambiente, a solução ácida na solução alcalina $\left(\mathrm{NaOH}\right.$ ou $\left.\mathrm{KOH}, 6 \mathrm{~mol} \mathrm{~L}^{-1}\right)$, mantendo o $\mathrm{pH}$ final igual ou acima de 12. Com isso, conseguiu-se um precipitado contendo Fe e Ca com um baxíssimo teor de Al. O emprego de $\mathrm{KOH}$ visava evitar a introdução de íons $\mathrm{Na}^{+}$no meio, permitindo

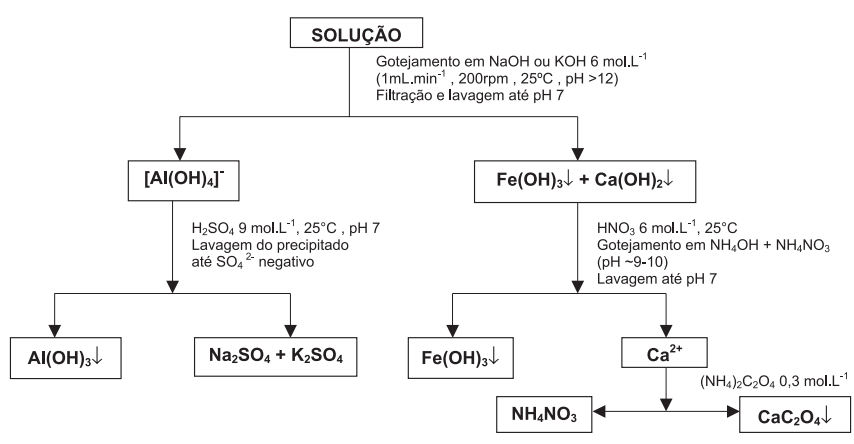

Figura 1. Esquema geral de fracionamento da solução aquosa obtida, após a fusão da peneira molecular com $\mathrm{KHSO}_{4}$ assim a dosagem do sódio do catalisador ao final do processo. A partir daí a separação $\mathrm{Fe}$ - Ca foi facilmente obtida por precipitação do primeiro como hidróxido em meio amoniacal tamponado entre 9-10; o cálcio foi precipitado como oxalato. O resíduo final é basicamente constituído por nitrato de amônio. A precipitação do Al foi feita por simples acidificação da solução com ácido sulfúrico, sendo que a etapa mais trabalhosa foi a lavagem do gel de hidróxido para livrá-lo dos íons sulfato, sódio e potássio adsorvidos. O resíduo final é constituído por uma solução de sulfatos de potássio e de sódio.

b) Fracionamento da solução - ZSM-5 (Figura 2): a etapa inicial é idêntica àquela aplicada ao caso da peneira molecular. De acordo com a química dos elementos presentes, ocorre a precipitação dos lantanídios, ferro, titânio e níquel, deixando o vanádio, o fosfato e o alumínio em solução. Este precipitado pode ser trabalhado de várias formas para isolar os elementos presentes: (a) dissolução em $\mathrm{HCl}\left(2 \mathrm{~mol} \mathrm{~L}^{-1}\right)$ seguido de tratamento com solução de $\left(\mathrm{NH}_{4}\right)_{2} \mathrm{C}_{2} \mathrm{O}_{4}\left(0,3 \mathrm{~mol} \mathrm{~L}^{-1}\right)$, precipitando seletivamente os lantanídeos ${ }^{21}$; (b) tratamento da solução após o isolamento dos latanídeos com tampão $\mathrm{NH}_{4} \mathrm{OH}+\mathrm{NH}_{4} \mathrm{Cl}$, precipitando $\mathrm{Fe}+$ Ti e deixando o Ni em solução ${ }^{19,20}$. Contudo, uma vez separados os lantanídios, os baixos teores de Ni, Fe e Ti podem não compensar o trabalho de isolamento dos mesmos e a conseqüente geração de resíduos salinos. Nesse caso, a simples neutralização da solução precipita estes elementos em forma adequada para envio ao incinerador, seguido de disposição em aterro industrial.

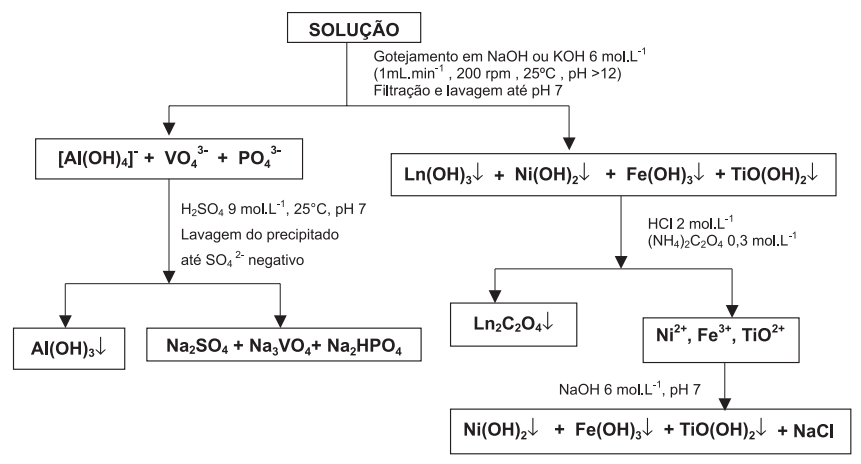

Figura 2. Fluxograma de separação dos elementos contidos na amostra de zeólita ZSM-5, após tratamento por fusão com $\mathrm{KHSO}_{4}$ e dissolução da massa fundida em água

Os resultados referentes à recuperação dos elementos figuram nas Tabelas 2 e 3. Eles se mostraram bastante satisfatórios. Os lantanídios podem ser utilizados diretamente na confecção de novas zeólitas (inserção na estrutura zeolítica - troca iônica) e/ou produtos de valor comercial, como outros catalisadores de uma forma geral. O precipitado de alumínio, na forma de hidróxido, junto com o resíduo de sílica, na forma de óxido, pode ser usado na confecção de zeólitas, com diferentes razões $\mathrm{Si} / \mathrm{Al}$ e diferentes estruturas cristalinas.

\section{Abertura com $\mathrm{HF}+\mathrm{H}_{2} \mathrm{O}_{2}$}

Em cerca de 30 min, a uma agitação de 400 rpm e temperatura de $60{ }^{\circ} \mathrm{C}$ ocorreu a solubilização-limite das zeólitas, sendo constatada a formação de um precipitado branco (peneira molecular) ou amarelo-marrom (ZSM-5). As análises por difração de raios-X acusaram a presença de diversas fases cristalinas: fluoretos e hexafluoroaluminossilciatos de lantanídios (ZSM-5); hexafluoroaluminatos de sódio e cálcio (peneira molecular), o que permite escrever as reações seguintes: 
Tabela 2. Distribuição dos metais* pelas frações obtidas - fusão com $\mathrm{KHSO}_{4}$ : ZSM-5

\begin{tabular}{|c|c|c|c|c|}
\hline \multirow[t]{2}{*}{ Fração } & \multicolumn{3}{|c|}{ Metais } & \multirow[t]{2}{*}{ Notas } \\
\hline & $\mathrm{Ni}$ & $\mathrm{Fe}$ & $\mathrm{Al}$ & \\
\hline Resíduo insolúvel da fusão em água & desprezível & desprezível & desprezível & Somente $\mathrm{SiO}_{2}$ \\
\hline Precipitado de Ni, Fe, Ti e lantanídeos & $99,95 \pm 0,05 \%$ & $99,00 \pm 0,05 \%$ & $0,90 \pm 0,03 \%$ & $\begin{array}{l}\text { Ti detectado por testes em via } \\
\text { úmida apenas nesta fração }\end{array}$ \\
\hline $\begin{array}{l}\text { Precipitado de } \mathrm{Al}(\mathrm{OH})_{3} \\
\text { Resíduo líquido final neutralizado }\end{array}$ & $\begin{array}{c}0,05 \pm 0,01 \% \\
\text { desprezível }\end{array}$ & $\begin{array}{l}1,00 \pm 0,02 \% \\
\text { desprezível }\end{array}$ & $\begin{array}{r}99,00 \pm 0,20 \% \\
0,10 \pm 0,01 \%\end{array}$ & $\overline{\text { Solução incolor sem turbidez }}$ \\
\hline
\end{tabular}

* obtidos por absorção atômica. Valores expressos em \% p/p com intervalo de confiança a 95\%

Tabela 3. Distribuição dos metais* pelas frações obtidas - fusão com $\mathrm{KHSO}_{4}$ : peneira molecular

\begin{tabular}{|c|c|c|c|c|c|}
\hline \multirow[t]{2}{*}{ Fração } & \multicolumn{4}{|c|}{ Metais } & \multirow[t]{2}{*}{ Notas } \\
\hline & $\mathrm{Fe}$ & $\mathrm{Ca}$ & $\mathrm{Al}$ & $\mathrm{Na}$ & \\
\hline Resíduo insolúvel da fusão em $\mathrm{H}_{2} \mathrm{O}$ & desprezível & desprezível & desprezível & desprezível & Somente $\mathrm{SiO}_{2}$ \\
\hline Precipitado de $\mathrm{Fe}(\mathrm{OH})_{3}$ & $99,60 \pm 0,09 \%$ & desprezível & $0,05 \pm 0,01 \%$ & desprezível & - \\
\hline Precipitado de $\mathrm{CaC}_{2} \mathrm{O}_{4}$ & $0,40 \pm 0,01 \%$ & $99,84 \pm 0,11 \%$ & desprezível & desprezível & - \\
\hline Precipitado de $\mathrm{Al}(\mathrm{OH})_{3}$ & desprezível & $0,11 \pm 0,02 \%$ & $99,90 \pm 0,03 \%$ & $0,62 \pm 0,18 \%$ & - \\
\hline Resíduo líquido final neutralizado & desprezível & $0,05 \pm 0,01 \%$ & $0,05 \pm 0,01 \%$ & $99,38 \pm 0,41 \%$ & $\begin{array}{l}\text { Solução incolor sem } \\
\text { precipitado }\end{array}$ \\
\hline
\end{tabular}

* obtidos por absorção atômica. Valores expressos em \% p/p com intervalo de confiança a 95\%

ZSM-5

$\mathrm{Ln}_{2} \mathrm{O}_{3}+\mathrm{HF} \rightarrow 2 \underline{\mathrm{LnF}}_{3}+3 \mathrm{H}_{2} \mathrm{O}$

$\mathrm{Ln}_{2} \mathrm{O}_{3}+12 \mathrm{HF}+\mathrm{Al}_{2} \mathrm{O}_{3} \rightarrow 2 \mathrm{LnAlF}_{6}+6 \mathrm{H}_{2} \mathrm{O}$

Peneira Molecular:

$3 \mathrm{Na}_{2} \mathrm{O}+12 \mathrm{HF}+\mathrm{Al}_{2} \mathrm{O}_{3} \rightarrow 2 \underline{\mathrm{Na}}_{3} \underline{\mathrm{AlF}}_{6}+6 \mathrm{H}_{2} \mathrm{O}$

$3 \mathrm{CaO}+12 \mathrm{HF}+\mathrm{Al}_{2} \mathrm{O}_{3} \rightarrow \underline{\mathrm{Ca}}_{3}\left(\underline{\mathrm{AlF}}_{6}\right)_{2}+6 \mathrm{H}_{2} \mathrm{O}$

Essas reações mostraram-se muito prejudiciais à recuperação de vários elementos; são evidentes as perdas de cálcio, sódio e alumínio no processamento da peneira molecular; embora a precipitação do cálcio e do sódio tenha sido quantitativa, a separação de ambos era impraticável, o que levava a uma perda considerável no isolamento do alumínio. Já no caso da ZSM-5, o panorama era bem menos drástico: apenas os lantanídios (no conjunto) precipitaram de forma quantitativa. Isso reflete a ausência de metais alcalinos e alcalino-terrosos nesta amostra, o que leva à imediata conclusão de que o emprego da mistura $\mathrm{HF}+\mathrm{H}_{2} \mathrm{O}_{2}$ para zeólitas (e outros catalisadores) contendo tais elementos não era recomendável, face a dificuldade em manipular um resíduo insolúvel e as sérias perdas na recuperação do alumínio.

Após o isolamento da massa insolúvel, procedeu-se ao isolamento do alumínio (como criolita, $\mathrm{Na}_{3} \mathrm{AlF}_{6}$ ) e da maior parte do silício, como $\mathrm{Na}_{2} \mathrm{SiF}_{6}$. O fluxograma da Figura 3 ilustra esta etapa. É necessário enfatizar que a adição de solução de $\mathrm{NaOH}$ deve ser feita bem lentamente, sob agitação (cerca de $1 \mathrm{~mL} \mathrm{~min}^{-1}$ ); do contrário, uma adição mais rápida leva a perdas de $\mathrm{Al}$ como $\left[\mathrm{Al}(\mathrm{OH})_{4}\right]$. A diferença no $\mathrm{pH}$ final segundo a zeólita considerada é devida à composição das mesmas: no caso da ZSM-5, se o pH fosse levado até 7, ocorreria a precipitação do Ti, V, P e Ni juntamente com o Al e o Si, contaminando os produtos finais a serem obtidos. Após secagem da massa branca, a composição da mesma acusou que a criolita era o composto predominante $(72 \%$ p/p de para a ZSM-5 e 55\% p/p para a peneira molecular). Essa diferença de composição reflete o maior teor de $\mathrm{Al}$ na primeira amostra. Na separação dos dois fluorossais, empregou-se água (10 $\mathrm{mL} \mathrm{g}^{-1}$ de sólido).
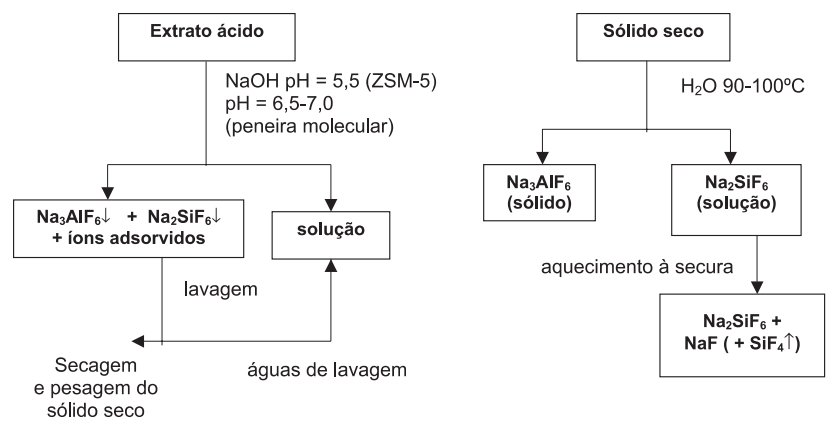

Figura 3. Fluxograma de isolamento do alumínio e do silício contidos nas zeólitas ZSM-5 e peneira molecular, após tratamento com misturas de HF $+\mathrm{H}_{2} \mathrm{O}_{2}$

Em ambos os casos, a criolita isolada tinha pureza de mais de $99,5 \% \mathrm{p} / \mathrm{p}$, contendo pequenas quantidades de $\mathrm{NaF}$, podendo ser empregada diretamente na metalurgia do alumínio ou como "agente desmoldante" no lingotamento do ferro. O rendimento em isolamento do alumínio foi de $99,5 \%$ p/p para a zeólita ZSM-5 e 75\% p/p para a peneira molecular, face às perdas oriundas na etapa de abertura desta amostra, como comentado anteriormente. No caso do silício, a análise do $\mathrm{Na}_{2} \mathrm{SiF}_{6}$ isolado mostrou que se tratava, na verdade, de uma mistura de $90 \%$ p/p do composto acima e de $10 \%$ p/p de NaF, explicável pela decomposição abaixo ocorrida durante a evaporação da solução:

$\mathrm{Na}_{2} \mathrm{SiF}_{6} \rightarrow 2 \mathrm{NaF}+\mathrm{SiF}_{4}$ (gás)

$\mathrm{O}$ rendimento em isolamento do silício nesta etapa variou entre $72 \%$ p/p (ZSM-5) e 65\% p/p (peneira molecular). Quanto às emana- 
ções de $\mathrm{SiF}_{4}$, borbulhou-se o efluente em água $\left(10{ }^{\circ} \mathrm{C}\right)$, originando uma solução de HF (empregada na neutralização da solução após o isolamento do níquel - ver adiante) e um precipitado de ácido silícico.

Para a peneira molecular, uma vez isolada a criolita, procedeu-se à evaporação da solução. Trata-se simplesmente da recuperação do silício residual presente na solução, contendo ainda $\mathrm{NaF}$ oriundo do excesso de HF usado na dissolução do catalisador. Obteve-se deposição de um sólido branco fosco; durante o processo, detectou-se fumos de $\mathrm{SiF}_{4}$ (tratado como acima) com conseqüente geração de mais $\mathrm{NaF}$ e perda de rendimento de isolamento do silício. O sólido tinha em média $85 \%$ p/p de $\mathrm{NaF}$ e $15 \%$ p/p de $\mathrm{Na}_{2} \mathrm{SiF}_{6}$; esta composição levava a um rendimento em recuperação de silício da ordem de $10 \% \mathrm{p} / \mathrm{p}$ do total inicial existente, elevando o rendimento global para $75 \% \mathrm{p} / \mathrm{p}$.

Para a zeólita ZSM-5, de posse da solução sem alumínio, de tonalidade esverdeada, adicionou-se $\mathrm{NaOH}\left(6 \mathrm{~mol} \mathrm{~L}^{-1}, \sim 1 \mathrm{~mL} \mathrm{~min}^{-1}\right)$ até $\mathrm{pH} 9,0-9,5$, visando a precipitação do níquel como $\mathrm{Ni}_{3}\left(\mathrm{PO}_{4}\right)_{2}$. Este sólido, verde, foi lavado com água a $60{ }^{\circ} \mathrm{C}\left(3 \mathrm{~mL} \mathrm{~g}^{-1}\right.$ precipitado). As análises deste sólido apresentam uma recuperação quantitativa de níquel, sem detecção de vanádio e de titânio.

À solução foi adicionado HF (20 $\left.\mathrm{mg} \mathrm{mL}^{-1}\right)$ até $\mathrm{pH} 7$, sendo depois evaporado à secura. Obteve-se um sólido branco fosco contendo tipicamente (\% p/p): $\mathrm{Na}_{2} \mathrm{SiF}_{6}, 50 ; \mathrm{NaF}, 50 ; \mathrm{Ti}$ e $\mathrm{V}$, menos que 0,$01 ; \mathrm{P}$, menos que 0,05 . Ele não pode ser descartado no ambiente (pois o íon $\mathrm{F}^{-}$é sério poluente ambiental); tampouco pode ir in natura para aterros industriais (porque é um material lixiviável pela chuva com o tempo). A solução pode ser um tratamento com $\mathrm{Ca}(\mathrm{OH})_{2} /$ $\mathrm{Na}_{2} \mathrm{CO}_{3}$, seguido de envio a um aterro industrial para materiais perigosos (Classe I) ou ainda empregá-lo como lubrificante siderúrgico no lingotamento do ferro.

\section{CONCLUSÕES}

$\mathrm{O}$ uso de $\mathrm{KHSO}_{4}$ como fundente mostrou-se muito eficiente na abertura do catalisador, permitindo, conseqüentemente, um fracionamento bastante amplo dos componentes das zeólitas estudadas. Também se teve como benefício a obtenção de resíduos finais de baixa toxicidade, apesar de se tratar de um efluente com alta salinidade. O elevado rendimento em recuperação dos componentes do catalisador, em condições mais brandas que as consideradas clássicas (oxidações a altas temperaturas e longos tempos), e sua aplicação direta em escala industrial - possibilidade de reaproveitamento total do catalisador - pode justificar a viabilidade do processo.

A dissolução em meio contendo $\mathrm{HF}+\mathrm{H}_{2} \mathrm{O}_{2}$ de catalisadores zeolíticos desativados pode ocorrer em tempo curto, permitindo o isolamento direto de aditivos de alto valor agregado, como os lantanídeos. O sucesso deste procedimento mostra a aplicabilidade do processo de dissolução em meio contendo fluoreto, inicialmente aplicado a catalisadores à base de alumina $\left(\mathrm{NiMo}, \mathrm{CoMo} / \mathrm{Al}_{2} \mathrm{O}_{3}, \mathrm{Pt} /\right.$ $\mathrm{Al}_{2} \mathrm{O}_{3}$, etc $)^{17}$, para amostras contendo simultaneamente silício e alumínio, contanto que a amostra não contenha metais alcalinos ou alcalino-terrosos, pois neste caso, ocorreu abundante precipitação do Al como criolita $\left(\mathrm{Na}_{3} \mathrm{AlF}_{6}\right)$ e do $\mathrm{Ca}\left(\mathrm{CaF}_{2}+\mathrm{Ca}_{3}\left(\mathrm{AlF}_{6}\right)_{2}\right)$, comprometendo a recuperação dos referidos elementos em formas reutilizáveis industrialmente com rendimento satisfatório. A obtenção de fluoretos de valor comercial (criolita e $\mathrm{NaF}+\mathrm{Na}_{2} \mathrm{SiF}_{6}$ ) reduziu grandemente o volume de resíduo gerado no processo. Este apresentou baixo con- sumo energético em comparação aos tradicionais procedimentos piroou hidrometalúrgicos aplicados para insolubilizar as zeólitas para descarte em aterros industriais, ou ao co-processamento em fornos de cimenteiras. Estuda-se a aplicação dos métodos apresentados neste trabalho a outras zeólitas contendo diferentes proporções de Si e Al, enfocando principalmente o isolamento final desses elementos em seus fluorocomplexos, bem como a amostras comerciais contendo outros aditivos $(\mathrm{Cs}, \mathrm{Eu}, \mathrm{Cr}, \mathrm{Cu}, \mathrm{Nb})$ e averiguar a recuperação dos mesmos após o tratamento da amostra.

\section{AGRADECIMENTOS}

E. S. Santos, M. S. Menezes e R. M Aguiar agradecem ao PBIC CNPq/SR-2-UFRJ a concessão de bolsas de iniciação científica.

Ao CNPq, FUJB (Fundação Universitária José Bonifácio), CENPES e à Fundação de Amparo à Pesquisa do Estado do Rio de Janeiro (FAPERJ), pelo auxílio financeiro. Ao Laboratório de Desenvolvimento Analítico (LADA/DQA/IQ/UFRJ) pelas análises por cromatografia de íons.

\section{REFERÊNCIAS}

1. Luna, F. J.; Schuchardt, U.; Quim. Nova 2001, 24, 885.

2. Luz, A. B.; Zeólitas: Propriedades e Usos Industriais, Série Tecnologia Mineral, CETEM/CNPq: Rio de Janeiro, 1995

3. Veloso, C. O.; Tese de Mestrado, Universidade Federal do Rio de Janeiro, Brasil, 1994

4. Câmara, L. D. T.; Tese de Mestrado, Universidade Federal do Rio de Janeiro, Brasil, 2001

5. Rupp, M. T. C.; Tese de Doutorado, Universidade Federal do Rio de Janeiro, Brasil, 1996.

6. Basset, J.; Denney, R. C.; Jeffery, G. H.; Mendham, J.; Análise Química Quantitativa, 6a. ed., Livros Técnicos e Científicos: Rio de Janeiro, 2002, caps. 10 e 11.

7. Clarifying the Scope of Petroleum Hazardous Waste Listings: Information Regarding Petroleum Hydroprocessing Units; U.S. Environmental Protection Agency, Office of Solid Waste: Washington, Junho 2001.

8. Petroleum Refining Listing Determination Proposed Rule Response to Comment Document, Part III; U.S. Environmental Protection Agency, Office of Solid Waste: Washington, Junho 1998.

9. Study of Selected Petroleum Refining Residuals - Industry Study; U.S. Environmental Protection Agency, Office of Solid Waste: Washington, Agosto 1996.

10. Clarifying the Scope of Petroleum Hazardous Waste Listings: Supplemental Information Regarding Petroleum Hydroprocessing Units; U.S. Environmental Protection Agency, Office of Solid Waste: Washington, Maio 2002.

11. Bader, N.; Oil and Gas Journal 1996, 64.

12. Huges, R.; Catalyst Deactivation, Academic Press: Londres, 1984.

13. Hazardous Waste Management System Identification and Listing of Hazardous Waste: Spent Catalysts from Dual-Purpose Petroleum Hydroprocessing Reactors; Federal Register 2002, 67, 30811

14. Trimm, D. L.; Appl. Catal., A 2001, 212, 153.

15. Su, N.; Chen, Z. H.; Fang, H. Y.; Cem. Concr. Compos. 2001, 23, 111.

16. Payá, J.; Monzó, J.; Borrachero, M. V.; Velázquez, S.; Cem. Concr. Res. 2003, 33, 603.

17. Afonso, J. C.; Lima, T. S.; Campos, P. C.; Pinheiro, A. A. S.; Quim. Nova 2003, 26, 924 .

18. Ohlweieler, O. A.; Teoria e Prática da Análise Quantitativa Inorgânica, $2^{a}$ ed., Livros Técnicos e Científicos: Rio de Janeiro, 1978, vol. 3.

19. Lurie, J.; Handbook of Analytical Chemistry, Mir Publishers: Moscou, 1978, caps. 3, 6 e 10.

20. Feigl, F.; Spot Tests in Inorganic Analysis, Elsevier: Amsterdam, 1958, cap. 3.

21. Abrão, A.; Química e Tecnologia das Terras Raras, CETEM/CNPq: Rio de Janeiro, 1994 